\title{
Determination of Economic Liberation and Mineralogical Characteristics of Nigerian Iron Ore for Effective Processing
}

\author{
O. O. Ola-Omole ${ }^{1,2}$, W. Nheta ${ }^{1}$ \\ ${ }^{1}$ Metallurgy Department, University of Johannesburg, South Africa \\ ${ }^{2}$ Metallurgical and Materials Engineering Department, Federal University of Technology Department, Federal University \\ of Technology, Akure
}

\begin{abstract}
Iron and steel play very important role in the economy of any nation because it is the yardstick for determining the rate of industrialisation of the countries. The present work studied the economic liberation and mineralogical characteristics of Nigerian low grade iron ore for effective processing. The ore studied was sourced from Itakpe an iron ore deposit in Nigeria. The sample was crushed sieved and characterized to understand the economic liberation and mineralogical characterization. Sieve analysis carried out based on the 2 method to choose 2300, 1700, 1180, 850, 600, 425, 300, 212, 150, 106, 75, and $63 \mu \mathrm{m}$ sieves. Thereafter, Scanning Electron Microscopy (SEM) and Xray diffraction was carried out to study the mineralogical characteristics of the sample. The results obtained shows that the economic liberation of Itakpe is between -425 and $+300 \mu \mathrm{m}$. The sample identity by SEM and XRD shows that the ore majorly contains hematite, magnetite and silica. It was therefore suggested that the ore can be concentrated by a combination of gravity separation method (jigging hydroclassifying or using the wifely shaking table) and magnetic separation to process the ore. Thereafter, more studies can investigation can be carried out to determine optimum parameters for flotation at lower particle sizes.
\end{abstract}

Keywords: hematite; magnetite; economic liberation; Scanning Electron Microscopy; Xray diffraction

\section{Introduction}

It The impact of iron and steel in any economy cannot be over emphasized because the rate of industrialisation on the nations are measured by the rate at which iron and steel are being produced and are consumed. The demand for iron and steel throughout the world increase on daily basis. The reason is not far fetch from the fact that metals are highly useful as they are the backbone of all engineering projects and products. Their uses vary from primitive tools of agriculture to advance aircrafts, automobiles, building and bridge construction, railways, light and heavy machinery and equipment shipping and transportation. Iron ores are major crude sources of iron. The crude ore cannot be smelted and refined without passing through the stages of mineral processing. There are two fundamental operations in mineral processing, the comminution which is also known as the release of valuable minerals from their waste gangue and the concentration, which is the separation of valuable minerals from the gangue [1]. Liberation is accomplished by comminution which is via crushing and grinding of the ore to a particular size to ensure that the valuable minerals are freed from the gangue. The economic liberation however means that the more of the valuable minerals are liberated or freed at this particle size. Therefore, more of the valuable minerals can be recovered at that particle size. If the sample is concentrated at less particle size, it can result in slime formation in which case more values are lost to the tailings. However, if larger particles are engaged in the concentration process, two things are likely going to happen; the minerals may not float well or too much reagents may be needed before attaining optimum recovery. Since crushing and grinding consumed greater than 50\% of cost of energy in mineral processing plants, the importance of knowledge of economic liberation is very crucial in the sense that time and energy will be saved during processing operations.

Effects of particle sizing cannot also be overemphasized in any mineral concentration because it establishes the quality of grinding and the degree of liberation especially of valuable minerals from gangue at various size ranges. This is why the methods employed for size analysis must be accurate and reliable. It is not a gainsaying that liberation of mineral particles of an ore is one of the most important parameter in mineral processing, especially in flotation. Ores need to be properly crushed and ground for adequate liberation to be achieved whereby the valuable minerals are freed from the gangue. This is when separation can be properly done.

Mineralogical characterisation is very crucial in the determination of process route for any ore deposit. The knowledge of which mineral is present in the ores and at what quantity and quality is a determining factor for the viability of the deposit. Several authors have studied the iron ore deposit of Itakpe and have reported various findings 
about the deposit yet the economic liberation have not been reported in the literatures. [2] studied how to predict the concentration characteristics of Itakpe iron ore for cut-off Grade Estimation. A model was developed to establish a functional relationship between ore grades and concentration characteristics of the deposit. The Wilcoxon signed rank test was used to establish a significant level of correspondence between actual values and values obtained from the model. It was reported that the model predicted that both the performance characteristics of the processing plant and the grade of the ore play vital roles in deciding the concentration characteristics of the ore. [3] reported that the mine has an estimated reserve of about 145 million tons of ore with $36 \%$ iron grade. He also reported that the deposit lies in the banded iron formation (BIF) which occurs in metamorphosed folded bands associated with Precambrian basement complex rocks which include low grade metasediments, high grade schists, gneisses, and migmatites. The banded iron formation occurs in narrow bands and lenses, interbedded with phyllites and schists. The iron formation bands vary in thickness from about 3 $\mathrm{cm}$ to $5 \mathrm{~cm}$. These reports show that the deposit is rich in iron. Nevertheless, there is need to carry out more investigations to confirm that the deposit is viable economically.

Elemental analysis of Itakpe by XRF has been carried out and it was discovered the deposit is majorly composed of $\mathrm{Fe}$ (29.55\% wt) and $\mathrm{Si}(24.68 \% \mathrm{wt})$ according to [4].

[5] studied the chemical and mineralogical characterization of Itakpe iron ore mine wastes (tailings). The results of their findings show that the ore dumped tailings contains majorly $27.71 \% \mathrm{Fe}_{2} \mathrm{O}_{3}, 70.1 \% \mathrm{SiO}_{2}, \mathrm{C}, \mathrm{Ti}, \mathrm{Al}, \mathrm{Mn}, \mathrm{Cu}$, and $\mathrm{O}$. The work concluded that the characteristic coarsely packed nature of the minerals present in the ore matrix will foster easier liberation of the iron ore from the gangue by comminution. This means that it is imperative to work on determination of the economic liberation of the minerals to actually ascertain at which particle size can the iron ore be processed to achieve an ultimate recovery of the valuable constituents. It is also important to determine the processing method that could be most effective and environmental friendly. This is therefore, the thrust for this study which centred on determination of economic liberation and mineralogical characterization of the Itakpe iron ore deposit and to suggest effective processing method for the deposit.

\section{Materials and Methods}

\subsection{Ore sourcing and preparation}

Iron ore used for this investigation was sourced from Itakpe iron ore deposit on Longitude $6^{\circ} 18^{\prime} 35^{\prime \prime} \mathrm{E}$ and Latitude $07^{\circ} 36^{\prime} 20^{\prime \prime}$ Nigeria. About $4 \mathrm{~kg}$ of the ore was collected and taken to the mineral processing laboratory for comminution. The sample was first broken with a sledge hammer which reduced the ore to pieces or smaller pebble of about 6 inches and below which can be fed into a Denver jaw crusher with an opening of more than 6 inches gape. The samples were fed into the crusher and crushed to sizes less than 6 inches, which were further reduced with FRITSCH laboratory jaw crusher pulverisette of 6 inches gape and 1 inch set ( Figure 1).

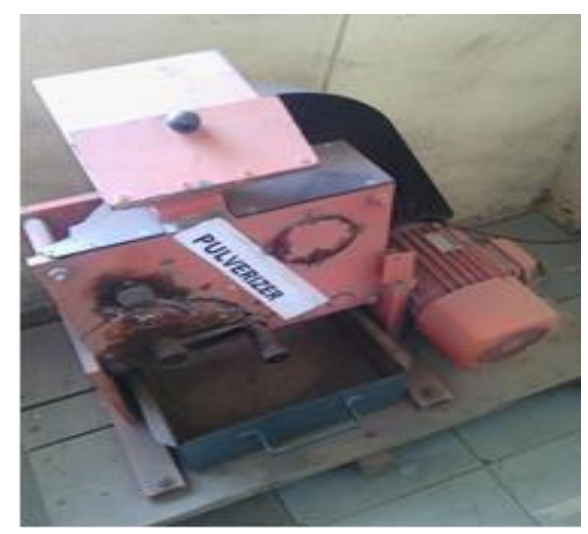

Fig 1: FRITSCH laboratory jaw crusher Pulverisette used for Comminution 
The resulting product was thoroughly mixed and equally divide into four parts using conning and quartering method to get the true representation on the sample. One portion was charged into a Denver ball mill plus 10 steel balls of $16 \mathrm{~cm}$ diameter and $340 \mathrm{~g}$ each as the grinding media. The sample as milled for 15 minutes to allow for proper attrition between the ore particles.

\subsection{Sieve analysis}

$1000 \mathrm{~g}$ of the milled sample was weighed for sieve analysis. A set of Endecott standard test sieves which was selected based on the 2 method and comprised of sieves 2300, 1700, 1180, 850, 600, 425, 300, 212, 150, 106, 75, and $63 \mu \mathrm{m}$ was used for this purpose. These sieves were arranged in a descending order of aperture and the sample was thereafter placed on the uppermost sieve while a sieve lid was used to cover the sample to avoid loss. The whole set was placed on the sieve shaker and the machine was switched on to vibrate for 25 minutes during which the undersize particles passed through successive sieves until they were retained on sieve with aperture smaller than their diameter. The retained weight on each of the sieves was taken and recorded for calculation and the liberation size was determined.

\subsection{Mineralogical characterisation \\ 2.3.1 Scanning Electron Microscopy}

Morphological and qualitative analyses of the ore was performed using high resolution scanning Electron Microscopy using the JEOL JSM. 7600 SEM analyser equipped with Energy dispersing X-ray (EDX) facilities. The sample was coated with carbon powder so that the surface will be conductive. Very little quantity of the sample was placed on the sample holder which was placed inside the machine. The SEM provides information on the physical properties (the mineral grain size, structure, shapes and degree of association of major, minor and trace elements) of minerals, while EDX provides information on their chemistry. The SEM images were captured at three different microns, 30, 100 and 300 .

\subsubsection{X-Ray Diffraction}

X-Ray Diffraction was carried out to determine the phases present in the mineral and also to know maybe the phases are chemically or physically bounded. The sample was prepared using back loading system. After cleaning the sample holder and the back piece with acetone after filling the ring with enough sample in the ring just above the cup level the sample was then loaded. The test was thereafter carried out using a PANanalytical X'pert pro diffractometer with $\mathrm{X}^{\prime}$ elevator and variable divergence and receiving slits each set at $10 \mathrm{~mm}$ with $\mathrm{Nb}$ filtered Co $\alpha \mathrm{k}$ radiation. The sample was scanned at angle $2 \theta$ and the relative phase amounts (weights \%) were estimated using the Rietveld method. X'pert high score plus software was used for the analysis of the results.

\section{Results}

\subsection{Sieve analysis}

\subsubsection{Determination of Economic liberation size of Itakpe iron ore}

Figure 2 is the sieve analysis plot of Itakpe iron ore showing the economic liberation size. The economic liberation is $-425+300 \mu \mathrm{m}$. The knowledge of economic liberation of minerals have always been useful in mineral processing plants because it saves time and energy. Economic liberation can be determined by particle size distribution which have always been determined by sieve analysis of the mineral. In flotation, it has been confirmed that the different minerals float effectively at different particle sizes ranges from fine and coarse particles. The economic liberation however means that the more of the valuable minerals are liberated at this particle size therefore, more of the valuable mineral can be recovered at this particle size. If the sample is concentrated at less particle size, it can result in slime formation in which case more are values are lost to the tailings. However, if larger particles are engaged in the concentration process, two things are likely going to happen; the minerals may not float well or the too much reagents may be needed before attaining optimum recovery. Therefore, for Itakpe iron ore, a combination of gravity separation 
method (jigging hydroclassifying or using the wifely shaking table) and magnetic separation can be engaged to process the ore to reduce the gangue. Thereafter, more studies can investigation can be carried out to determine optimum parameters for flotation at lower particle sizes lower than -425 to $+300 \mu \mathrm{m}$.

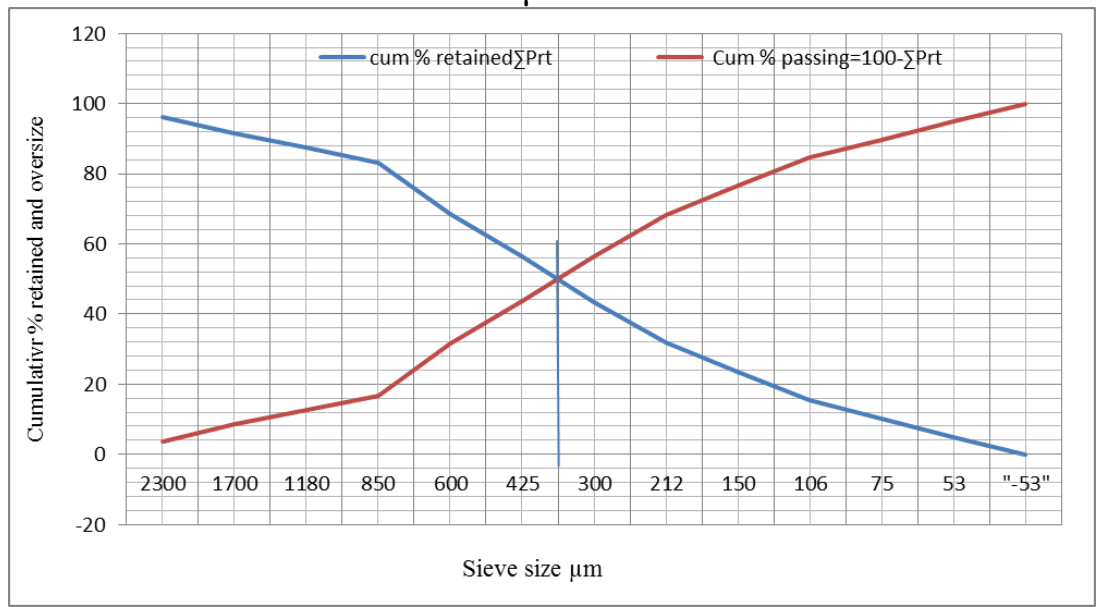

Fig 2: Sieve analysis plot of Itakpe iron ore showing the point of economic liberation.

\subsubsection{Determination of cumulative \% passing and the value of $\mathbf{R}^{2}$ of Itakpe iron ore by sieve analysis}

The results show that $80 \%$ passing corresponds to sieve range of $+150-106 \mu \mathrm{m}$ which shows that greater percentage of the sample actually passed through successive finer mesh meaning that even finer aggregates of the pulverized ore particles were obtained in good proportions lesser than that of the larger particles which were retained on the larger mesh sizes. The Regression line of cumulative \% shows that the value of $\mathrm{R}^{2}$ for the graphs 0.98 which points to degree of perfectness of the graph as it is very close to 1 . This means that the ore has a very good bonding and this will enhance good liberation of the values from the gangue. However, the economic liberation size for crushing of the ore is $380 \mu \mathrm{m}$ at $50 \%$. This mean that $50 \%$ liberation is achieved with effect from any value after $380 \mu \mathrm{m}$ downward. Knowing fully that greater percentage of cost of mineral processing is expended on crushing and grinding, the knowledge of crushing and grinding criteria for obtaining a good liberation is highly imperative because time and resources will not be wasted in crushing and grinding.

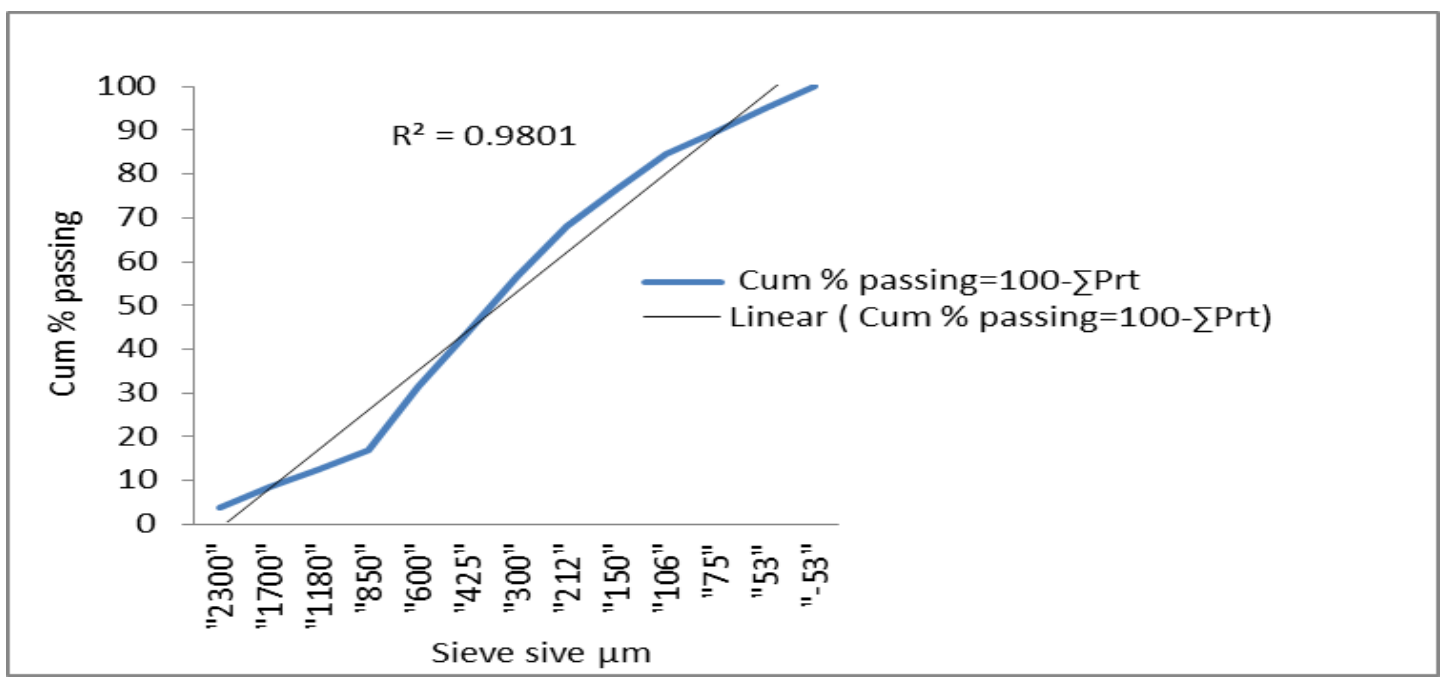

Fig 3: Graph of sieve analysis plot of Itakpe iron ore showing the Value of $\mathrm{R}^{2}$ of cumulative $\%$ passing 
Figure 4 shows the Gates-Gaudin-Schumman plot of Itakpe iron ore. This is almost a straight line graph when compared to the direct plot of cumulative $\%$ undersize versus sieve size. The graph is in which conformity to the normal standard graph of log-log plot. The advantage of the graph is that interpolation of result is much more easier, thus relieving the burden of routine analysis because fewer sieves can be selected for determination of size distribution.

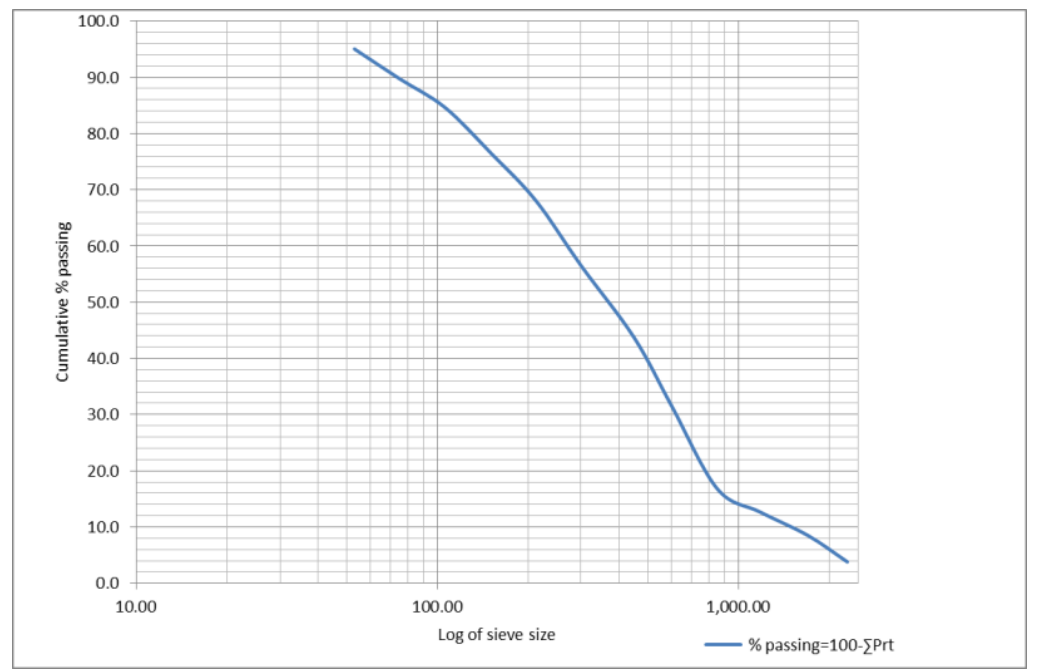

Fig 4: Gates-Gaudin-Schumman plot of Itakpe iron ore.

Figures 5, 6, and 7 show the SEM analyses of Itakpe iron ore showing the morphology of the deposit. There are presence of large, small and medium particles of irregular shapes as shown in the micrographs. From the figures, it can be seen that the grains of elements in the sample were of different sizes and brighter than one another. Regions of high average atomic number appear brighter relative to regions of low atomic number. In other words: the heavier the element, the lighter the colour. Therefore, magnetite and haematite exhibit the more lighter colour while silica and goethite exhibit the next lighter colour as their Molecular weight were closer to each other. At $30 \mu \mathrm{m}$ the peaks of Fe, Si and O2 were well pronounced on the spectrum and other elements ( $\mathrm{Ca}, \mathrm{Cu}, \mathrm{Al}, \mathrm{P}$ and $\mathrm{S}$ ) were also seen to be present in the ore. Percentage weight of each of these elements were automatically recorded in Table 1. Comparing the weight percentages with their corresponding peaks, it can be ascertained that Itakpe iron ore comprise of $\mathrm{Fe}, \mathrm{Si}$ and $\mathrm{O}$ as the major elements. Moreover, at $100 \mu \mathrm{m}$ the peaks of $\mathrm{Fe}, \mathrm{Si}$ and $\mathrm{O} 2$ were still present, but not well pronounced on the spectrum as in $30 \mu \mathrm{m}$ only $\mathrm{P}$ was seen as trace element. Percentage weight of each of the elements were automatically recorded in Table 2. However, at 600 $\mu \mathrm{m}$, Si was seen as the only element with pronounced peak even though Fe was present but at a very low concentration so also $\mathrm{Ca}$ and $\mathrm{P}$ at a much lower concentrations and this was also confirmed on the Table 3 . This is to ascertain the liberation is a function of the size of particle within ore matrix. 

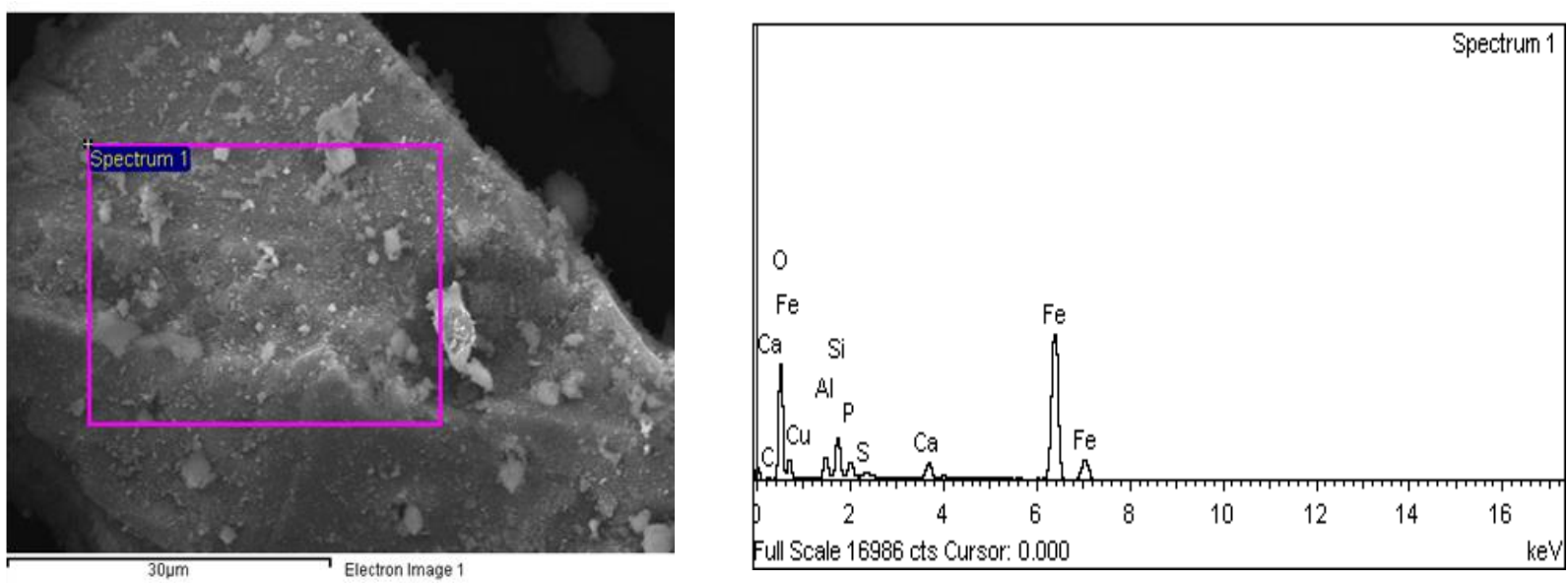

Fig 5: SEM analysis of Itakpe iron ore by Energy Dispersive X-ray Spectroscopy (30 $\mu \mathrm{m})$

Table 1: Elemental analysis of Itakpe by $\operatorname{EDX}(30 \mu \mathrm{m})$

\begin{tabular}{|c|c|c|c|c|c|c|c|c|}
\hline Element & $\mathrm{C}$ & $\mathrm{O}$ & $\mathrm{Al}$ & $\mathrm{Si}$ & $\mathrm{P}$ & $\mathrm{Fe}$ & $\mathrm{Ca}$ & $\mathrm{Cu}$ \\
\hline Weight $\%$ & 4.3 & 43.7 & 3.0 & 5.2 & 2.0 & 39.4 & 1.8 & 0.3 \\
\hline
\end{tabular}
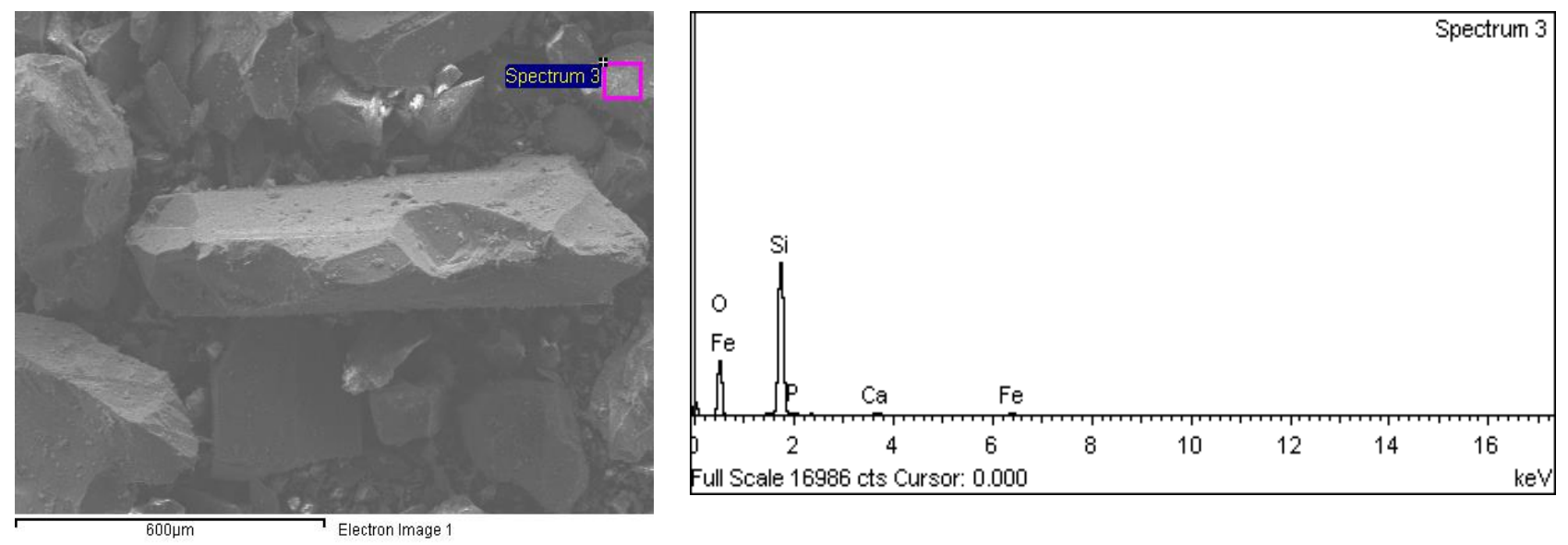

Fig 6: SEM analysis of Itakpe iron ore by Energy Dispersive X-ray Spectroscopy $(100 \mu \mathrm{m})$

Table 2: Elemental analysis of Itakpe by EDX $(100 \mu \mathrm{m})$

\begin{tabular}{|l|l|l|l|l|l|l|}
\hline Element & $\mathrm{C}$ & $\mathrm{O}$ & $\mathrm{Si}$ & $\mathrm{P}$ & $\mathrm{Fe}$ & $\mathrm{Ca}$ \\
\hline Weight $\%$ & 5.05 & 45.13 & 3.51 & 1.05 & 44.51 & 0.75 \\
\hline
\end{tabular}



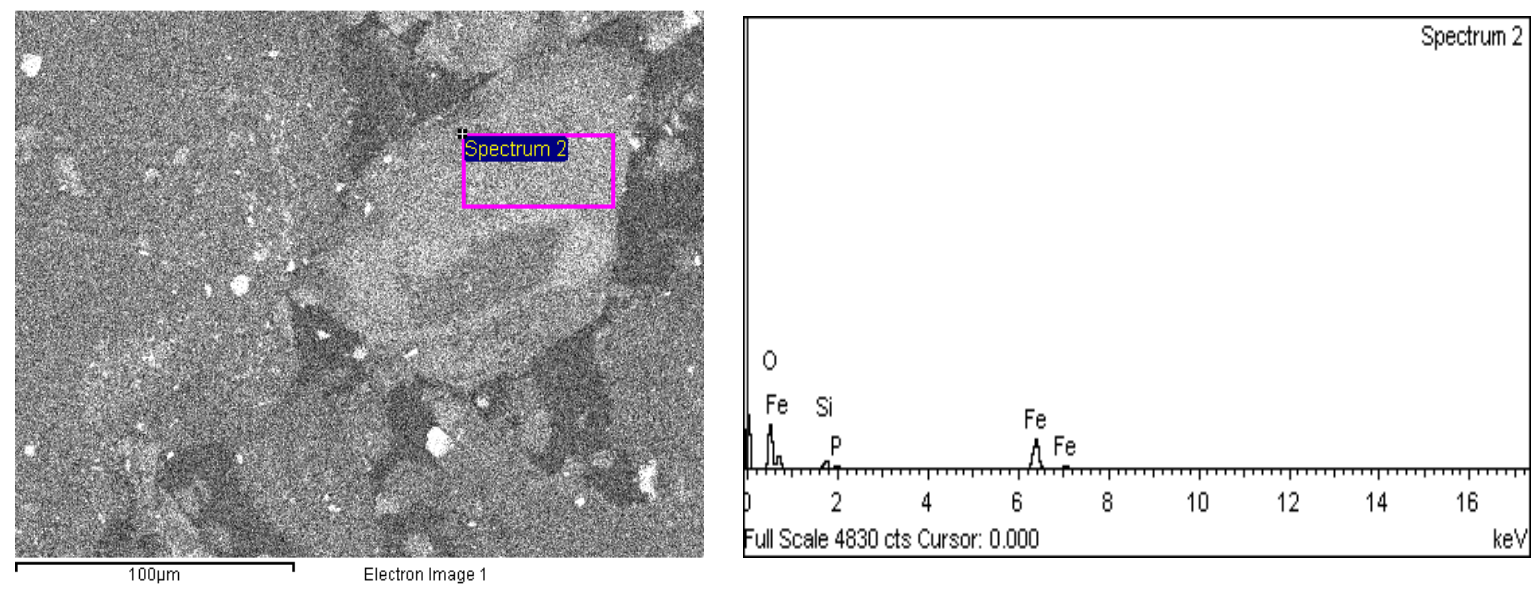

Fig 7: SEM analysis of Itakpe iron ore by Energy Dispersive X-ray Spectroscopy $(600 \mu \mathrm{m})$

Table 3: Elemental analysis of Itakpe by $\operatorname{EDX}(600 \mu \mathrm{m})$

\begin{tabular}{|l|l|l|l|l|l|l|l|l|}
\hline Element & $\mathrm{C}$ & $\mathrm{O}$ & $\mathrm{Al}$ & $\mathrm{Si}$ & $\mathrm{P}$ & $\mathrm{Fe}$ & $\mathrm{Ca}$ & $\mathrm{Cu}$ \\
\hline Weight $\%$ & 4.58 & 59.79 & 3.0 & 31.89 & 1.08 & 0.87 & 0.87 & 0.3 \\
\hline
\end{tabular}

Figure 8 shows the Xray Diffraction Pattern of Itakpe iron ore. The XRD pattern shows that there is magnetite 21.2\% and hematite $72.1 \%$ dominant minerals. Meanwhile Geothite and quartz are also present as gangue minerals. The peaks also revealed traces of other minerals are embedded in the ore matrix. The results has ascertained that the sample is rich in iron. However, X-ray diffraction is very accurate in quantifying the major components within a sample [6]. Therefore, the presence of elements discovered through the SEM images corroborates the minerals contained in the ores. Hematite and magnetite are Fe rich mineral while Silica and geothite are reach in $\mathrm{Si}$.

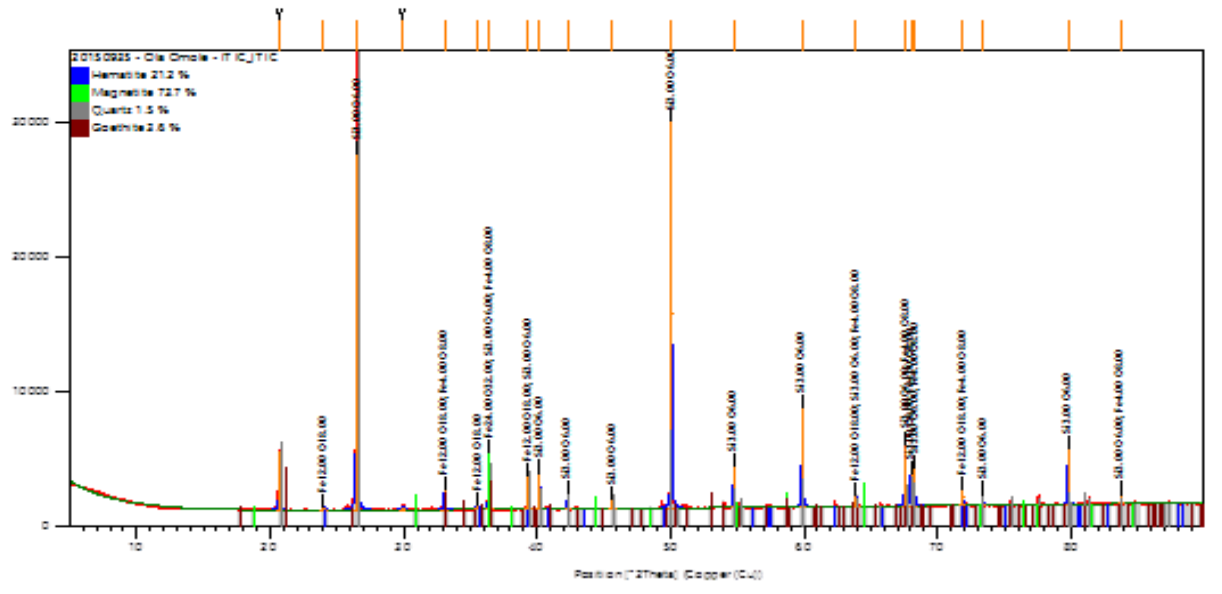

Fig 8: X-Ray Diffraction Pattern of Itakpe iron ore.

\section{Conclusion}

In this paper, economic liberation and mineralogical characteristic of Nigerian iron ore for effective processing were investigated. Sieve size, morphological and qualitative analyses of ores were performed and the economic liberation of Itakpe was found to be $-425+300 \mu \mathrm{m}$. The sample shows that the ore majorly contains hematite, magnetite and silica. A 
according to ISO 9001:2015, hematite has a specific gravity of 5.4, magnetite is between 4.9 and 5.2, while that of silica is 2.6 suggesting that the ore can be processed using gravity separation method in which case the valuable minerals magnetite and hematite are heavier than silica which is the major gangue. The ore can therefore be concentrated by a combination of gravity separation method (jigging hydroclassifying or using the wifely shaking table) and magnetic separation. Flotation can also be engaged after reducing the silica content of the ore. This means a further investigation can be made to understand the optimum parameters for floating the mineral content.

\section{References}

[1] D. Portnikov, and H. Kalman, "Material comminution functions of wet particles", Powder Technology, vol. 343, pp. 29-39, 2019.

[2] A. Alimi, J. I. Nwosu, and O. Kingsley, "Predicting the Concentration Characteristics of Itakpe Iron Ore for cut-off Grade Estimation", J. Appl. Sci. Environ. Manage, vol. 17, no. 2, pp. 315-319, 2013.

[3] E. Oniuwe, 2016, Geometric Interpretation of Itakpe Open Pit Mine [online]. Available: http://dx.doi.org/10.2139/ssrn.3466753.

[4] U.A. Uduma, , S.O. Ngele, and I.O. Alisi, "Elemental Analysis of Itakpe Iron Ore by Energy Dispersive X Ray Fluorescence Spectrometry", Bayero Journal of Pure and Applied Sciences, vol. 10, no. 1, pp. 234 - 237, 2017.

[5] O. O. Alabi, Y. Gbadamosi, T. A. Olatunji and O. O. Ola-Omole, "Chemical and Mineralogical Characterization of Itakpe Iron Ore Mine Wastes (Tailings)", Journal of raw material research development council, vol. 14, no. 2, 2019.

[6] A. Teissier, P.G.C. Campbell and M. Bisson, "Sequential extraction procedure for the speciation of particulate trace metal", Analytical Chemistry, vol. 51, pp 844-851,1979 